\title{
HUBUNGAN PERAWATAN PAYUDARA DENGAN KELANCARAN ASI PADA IBU NIFAS
}

\author{
Veronica Anggreni Damanik \\ Program Studi D3 Keperawatan, Fakultas Farmasi dan Kesehatan, \\ Institut Kesehatan Helvetia Medan, Indonesia \\ Email:veronica.damanik88@gmail.com
}

\begin{abstract}
ASI has the most complete nutritional composition and is ideal for infant growth and development during the first 6 months. However, only 39 percent of all babies in the world get exclusive breastfeeding and there are still many mothers who are less successful at breastfeeding or stop breastfeeding early. Based on Indonesia's Health Profile in 2016 the percentage of breastfeeding in Indonesia from 0-6 months infants was 29.5\%. This study aims to determine the relationship of breast care with the smoothness of breast milk in postpartum mothers at the Poskeskel Clinic in Medan. The design of this study was an analytic survey with cross sectional approach. The sampling technique is total sampling, a sample of 40 respondents. The research was conducted at the Poskeskel Clinic in Medan and in July-September 2018. Data analysis used was the Chi-Square test. The results of this study indicate that the p-value is $0.004(<\alpha 0.05)$, which means there is a relationship between breast care and the smoothness of breast milk in postpartum mothers. The conclusion is that there is a relationship between breast care, and the smoothness of breastfeeding in parturition mothers. It is advisable for postpartum mothers to care for the breasts after the baby is born and postpartum at least 2 times a day regularly and it is advisable for health workers to conduct counseling and demonstrate the steps of breast care for pregnant and lactating women so that the production of ASI is plenty and smooth.
\end{abstract}

\section{Keywords: breast care, smoothness of breast milk, puerperal women}

\section{PENDAHULUAN}

ASI (Air Susu Ibu) merupakan cairan kehidupan terbaik yang sangat dibutuhkan oleh bayi sampai 6 bulan karena mempunyai komposisi gizi yang paling lengkap dan ideal untuk pertumbuhan dan perkembangan bayi yang dapat memenuhi kebutuhan gizi bayi selama 6 bulan pertama. Tetapi, hanya 39 persen dari semua bayi di dunia yang mendapatkan ASI ekslusif. Menyusui merupakan proses alamiah namun selama ini masih banyak ibu yang tidak berhasil menyusi atau menghentikan menyusui lebih dini. Banyak alasan yang dikemukakan ibuibu yang tidak menyusui bayinya antara lain sibuk bekerja, takut gemuk, dan produksi ASI kurang lancar (Lusje, Mandan, \& Kusmiyati, 2014).

Berdasarkan data dari WHO tahun 2015 diperkirakan 130 juta bayi dilahirkan di dunia setiap tahun dan 4 juta bayi meninggal dalam 28 hari pertama kehidupannya. Menurunkan angka kesakitan, WHO merekomendasikan agar bayi baru lahir mendapat ASI ekslusif (tanpa tambahan makanan) 
paling sedikit enam bulan. Makanan padat seharusnya di berikan setelah enam bulan, dan pemberian ASI dilanjutkan sampai anak berusia dua tahun. Tahun 2011 hanya 35,5\% bayi berusia kurang dari 6 bulan di dunia mendapatkan ASI ekslusif, pada sidang kesehatan dunia ke-65 negara-negara anggota WHO menetapkan target di tahun 2025 bahwa sekurang-kurangnya $50 \%$ dari jumlah bayi di bawah usia enam bulan diberi ASI ekslusif (Saputri, Tri Muliani, 2017).

Profil Kesehatan Indonesia tahun 2016 persentase pemberian ASI di Indonesia dari bayi 0-6 bulan sebesar 29,5\%, sedangkan untuk pemberian ASI 0-5 bulan persentasenya sebesar $54,0 \%$. Provinsi Jawa Timur persentase pemberian ASI dari bayi 0-6 bulan sebesar 31,3\% sedangkan untuk pemberian ASI $0-5$ bulan $48,1 \%$ (Kemenkes, 2017).

Berdasarkan Profil Kesehatan Sumatera Utara tahun 2017, dari 296.443 bayi lahir hidup, jumlah bayi yang meninggal sebelum mencapai ulang tahun yang pertama berjumlah 771 bayi, perkiraan Angka Kematian Bayi (AKB) di Sumatera Utara tahun 2017 yakni 2,6/1.000 Kelahiran Hidup $(\mathrm{KH})$. Cakupan persentase bayi yang diberi ASI tahun 2017 mengalami peningkatan dibandingkan tahun sebelumnya. Kabupaten dengan pencapaian $>60 \%$ yaitu Simalungun (96,61\%), Labuhan Batu Utara $(89,41 \%)$, Samosir $(75,11 \%)$, Padang Sidempuan $(72,05 \%)$, Padang Lawas $(67,77 \%)$, Tebing Tinggi $(62,44 \%)$ dan Dairi $(61,6 \%)$. Terdapat 2 kabupaten dengan pencapaian $<10 \%$ yaitu Nias Utara $(7,86 \%)$ dan Padang Lawas Utara (9,30\%) (Dinas Kesehatan Provinsi Sumatera Utara, 2017).

Upaya yang dilakukan untuk menanggulangi permasalahn di atas, yaitu dengan melakukan perawatan payudara pada ibu menyusui, sehingga membantu pengeluaran ASI secara lancar. Perawatan payudara pada ibu nifas merupakan perawatan yang sebaiknya dilakukan untuk mempersiapkan payudara agar dalam kondisi baik saat menyusui bayinya, meliputi perawatan kebersihan payudara baik sebelum maupun sesudah menyusui. Perawatan putting susu yang lecet dan merawat putting susu agar tetap lemas, tidak keras, dan tidak kering (Suririnah, 2012)

Perawatan payudara merupakan upaya untuk merangsang sekresi hormon oksitosin untuk menghasilkan ASI sedini mungkin dan memegang peranan penting dalam menghadapi masalah menyusui. Tehnik pemijatan dan rangsangan pada putting susu yang dilakukan pada perawatan payudara merupakan latihan semacam efek 
hisapan bayi sebagai pemicu pengeluaran ASI (Rosita, 2017).

Perawatan payudara atau sering disebut Breast Care bertujuan untuk memelihara kebersihan payudara, memperbanyak atau memperlancar pengeluaran ASI. Tujuan perawatan untuk memperlancar produksi ASI dengan merangsang kelenjar-kelenjar air susu melalui pemijatan, mencegah bendungan ASI atau pembengkakan payudara, melenturkan dan menguatkan putting (Mochtar, 2015).

Hal ini juga sesuai dengan hasil penelitian (Safitri, Wijayanti, \& Werdani, 2016) tentang faktor-faktor yang mempengaruhi kelancaran produksi asi pada ibu menyusui di Desa Bendan, Kecamatan Banyudono, Kabupaten Boyolali yang menyatakan bahwa tidak ada pengaruh antara pelaksanaan inisiasi menyusui dini, ada pengaruh antara perawatan payudara, ada pengaruh antara penggunaan alat kontrasepsi, dan ada pengaruh antara keberadaan perokok pasif dengan kelancaran produksi ASI.

Merawat payudara baik selama kehamilan maupun setelah bersalin akan menjaga bentuk payudara dan memperlancar keluarnya ASI. Gerakan perawatan pada payudara selain bermanfaat melancarkan reflex pengeluaran ASI juga merupakan cara efektif meningkatkan volume ASI, serta tak kalah penting mencegah bendungan pada payudara (Saryono \& RD Pramitasari, 2014).

Menurut data WHO terbaru pada tahun 2015 di Amerika Serikat persentase perempuan menyusui yang mengalami bendungan ASI rata-rata mencapai $87,05 \%$ atau sebanyak 8242 ibu nifas dari 12.765 orang, pada tahun 2014 ibu yang mengalami bendungan ASI sebanyak 7198 orang dari 10.764 orang dan pada tahun 2015 terdapat ibu yang mengalami bendungan ASI sebanyak 6543 orang dari 9.862 orang (WHO, 2015).

Ibu nifas yang mengalami bendungan ASI di Indonesia tahun 2014 sebanyak 35.985 atau $(15,60 \%)$ ibu nifas. Ibu nifas yang mengalami bendungan ASI pada tahun 2015 sebanyak 77.231 atau (37,12\%) (SDKI, 2017).

Berdasarkan survei awal yang dilakukan kepada 10 ibu nifas, dimana 2 orang mengatakan melakukan perawatan payudara tetapi tidak rutin dan ASI tidak lancar, sedangkan 7 orang tidak pernah melakukan perawatan payudara dan ASI tidak lancar dan 1 orang mengalami bendungan ASI.

Berdasarkan uraian tersebut, peneliti tertarik untuk melakukan penelitian mengenai hubungan perawatan payudara dengan kelancaran ASI pada ibu nifas di Klinik Poskeskel Medan. 


\section{METODE}

Desain penelitian ini adalah survei analitik dengan pendekatan cross sectional yaitu penelitian yang mencoba menggali bagaimana dan mengapa fenomena itu terjadi. Penelitian ini dilakukan di Klinik Poskeskel Medan dan pada Juli-September 2018.

Populasi adalah sekelompok subjek yang menjadi objek atau sasaran penelitian, yang memiliki karakteristik tertentu dan ditetapkan oleh peneliti untuk dapat ditarik kesimpulan. Populasi yang diambil dalam penelitian ini adalah seluruh ibu nifas yang ada di wilayah Klinik Poskeskel Medan dari FebruariMaret 2018, yaitu sebanyak 40 responden. Sampel adalah bagian dari populasi yang dipilih berdasarkan teknik-teknik tertentu dan dapat mewakili populasinya (Notoatmodjo, 2012). Pengambilan sampel yang digunakan dalam penelitian ini adalah total sampling, yaitu sebanyak 40 responden.

Penelitian ini dilakukan dengan memberikan kuesioner variabel perawatan payudara yang terdiri dari 10 pernyataan tentang teknik perawatan payudara dan kuesioner kelancaran ASI yang terdiri dari 10 pernyataan tentang tanda-tanda kelancaran ASI.

Peneliti melakukan proses perijinan dan administrasi dengan pihak tempat penelitian. Kemudian, melakukan pengumpulan data primer dengan menyebarkan kuesioner dan wawancara door to door kepada ibu nifas, serta data sekunder yang diambil dari data rekam medik Klinik Poskeskel Medan.

Penelitian ini dilakukan analisa data secara univariat dan bivariat. Analisa univariat dengan melakukan analisis pada setiap variabel hasil penelitian dengan tujuan mengetahui distribusi frekuensi perawatan payudara dan kelancaran ASI pada ibu nifas. Analisa bivariat digunakan untuk mengetahui hubungan perawatan payudara dengan kelancaran ASI pada ibu nifas.

Analisa bivariat ini dilakukan dengan menggunakan perangkat lunak komputerisasi dengan uji Chi-square pada batas kemaknaan perhitungan statistik $p$ value < $(0,05)$. Apabila hasil perhitungan menunjukkan nilai $\mathrm{p}<0,05$ maka dikatakan $\left(\mathrm{H}_{0}\right)$ ditolak dan $\left(\mathrm{H}_{\mathrm{a}}\right)$ diterima, artinya kedua variabel mempunyai hubungan yang signifikan, yaitu ada hubungan perawatan payudara dengan kelancaran ASI pada ibu nifas.

\section{HASIL DAN PEMBAHASAN}

\section{Hasil Penelitian}

Berdasarkan hasil penelitian ini mendapatkan karakteristik responden yang dapat dilihat pada Tabel di bawah ini. 


\begin{tabular}{lrc}
$\begin{array}{l}\text { Tabel 1. Karakteristik } \\
\text { Berdasarkan } \\
\text { Pendidikan, dan }\end{array}$ & \multicolumn{2}{c}{$\begin{array}{c}\text { Responden } \\
\text { Umur, }\end{array}$} \\
\hline \multicolumn{1}{c}{ Karakteristik } & \multicolumn{1}{c}{$\boldsymbol{\%}$} & $\%$ \\
\hline $\begin{array}{l}\text { Umur } \\
\text { Remaja Akhir (17-25 }\end{array}$ & 11 & 27,5 \\
tahun) & & \\
$\quad \begin{array}{l}\text { Dewasa Awal (26-35 } \\
\text { tahun) }\end{array}$ & 21 & 52,5 \\
$\quad$ Dewasa Akhir (36-45 & 8 & 20,0 \\
tahun) & & \\
Pendidikan & & \\
$\quad$ SD & 4 & 10,0 \\
SMP & 17 & 42,5 \\
SMA & 13 & 32,5 \\
$\quad$ Sarjana & 6 & 15,0 \\
Paritas & & \\
$\quad$ Primipara & 25 & 62,5 \\
$\quad$ Multipara & 11 & 27,5 \\
$\quad$ Grandmultipara & 4 & 10,0 \\
\hline
\end{tabular}

Berdasarkan Tabel 1, diketahui bahwa dari 40 responden, sebanyak $52,5 \%$ yang berumur dewasa awal (2635 tahun), sebanyak $42,5 \%$ yang berpendidikan SMP, dan sebanyak $62,5 \%$ yang merupakan primipara (ibu yang pertama kali melahirkan).

Tabel 2. Distribusi

Frekuensi Berdasarkan Perawatan Payudara pada Ibu Nifas

\begin{tabular}{llcc}
\hline \multirow{2}{*}{ No } & $\begin{array}{l}\text { Perawatan } \\
\text { Payudara }\end{array}$ & \multicolumn{2}{c}{ Jumlah } \\
\cline { 2 - 4 } 1. & Tidak & 22 & \% \\
\cline { 2 - 4 } 2. & Melakukan & & \\
Melakukan & 18 & 45,0 \\
\hline & Total & $\mathbf{4 0}$ & $\mathbf{1 0 0}$ \\
\hline
\end{tabular}

Berdasarkan Tabel 2 diketahui bahwa dari 40 responden, yang tidak melakukan perawatan payudara sebanyak 22 orang $(55,0 \%)$ dan responden yang melakukan perawatan payudara sebanyak 18 orang $(45,0 \%)$.

\begin{tabular}{|c|c|c|c|}
\hline Tab & $\begin{array}{l}\text { I. Distribusi } \\
\text { Berdasarkan } \\
\text { ASI pada Ibu }\end{array}$ & $\begin{array}{r}\text { K } \\
\text { Nifas }\end{array}$ & $\begin{array}{l}\text { rekuensi } \\
\text { lancaran }\end{array}$ \\
\hline & & & imlah \\
\hline No & Kelancaran ASI & $f$ & $\%$ \\
\hline 1 . & Tidak Lancar & 20 & 50,0 \\
\hline 2. & Lancar & 20 & 50,0 \\
\hline Tot & & 40 & 100 \\
\hline
\end{tabular}

Berdasarkan Tabel 3 dapat diketahui bahwa dari 40 responden, yang ASInya tidak lancar sebanyak 20 responden $(50,0 \%)$ dan responden yang ASInya lancar sebanyak 20 responden (50,0\%).

Tabel 4. Tabulasi Silang Perawatan Payudara dengan Kelancaran ASI pada Ibu Nifas

\begin{tabular}{|c|c|c|c|c|c|c|c|}
\hline \multirow{3}{*}{$\begin{array}{c}\text { Perawatan } \\
\text { Payudara }\end{array}$} & \multicolumn{4}{|c|}{ Kelancaran ASI } & \multirow{2}{*}{\multicolumn{2}{|c|}{ Jumlah }} & \multirow{3}{*}{$\begin{array}{c}p \\
\text { value }\end{array}$} \\
\hline & \multicolumn{2}{|c|}{$\begin{array}{c}\text { Tidak } \\
\text { Lancar }\end{array}$} & \multicolumn{2}{|c|}{ Lancar } & & & \\
\hline & $f$ & $\%$ & $f$ & $\%$ & $f$ & $\%$ & \\
\hline Tidak & 16 & 72,7 & 6 & 27,3 & 22 & 55,0 & 0,004 \\
\hline Melakukan & & & & & & & \\
\hline Melakukan & 4 & 22,2 & 14 & 77,8 & 18 & 45,0 & \\
\hline Total & 20 & 50 & 20 & 50 & 40 & 100 & \\
\hline
\end{tabular}

Berdasarkan Tabel 4 diketahui bahwa dari 22 responden $(55,0 \%)$ yang tidak melakukan perawatan payudara terdapat 16 responden $(72,7 \%)$ yang ASInya tidak lancar dan 6 responden $(27,3 \%)$ yang ASInya lancar. Sedangkan dari 18 $(45,0 \%)$ responden yang melakukan perawatan payudara terdapat 4 responden $(22,2 \%)$ yang ASInya tidak lancar dan 14 responden $(77,8 \%)$ yang ASInya lancar.

Berdasarkan hasil uji statistik dengan Chi-Square diperoleh $p$ value 0,004 ( $p<$ $\alpha 0,05)$, yang berarti ada hubungan 
perawatan payudara dengan kelancaran ASI pada ibu nifas.

\section{Pembahasan}

\section{Hubungan Perawatan Payudara dengan Kelancaran ASI pada Ibu Nifas}

Berdasarkan hasil uji statistik dengan Chi-Square didapatkan ada hubungan perawatan payudara dengan kelancaran ASI pada ibu nifas. Sebagian besar ibu nifas yang tidak melakukan perawatan payudara mengalami kesulitan dalam memberikan ASI kepada bayinya dikarenakan payudara yang bengkak, putting susu lecet, putting susu yang tidak menonjol sehingga produksi ASI sedikit dan tidak lancar. Dengan begitu, tidak sedikit ibu nifas yang kurang berhasil memberikan ASI kepada bayinya dengan lancar.

Teori yang mendukung penelitian ini menyatakan bahwa perawatan payudara merupakan suatu kebutuhan hidup yang baru saja melahirkan dan ini suatu tindakan yang sangat penting untuk memperlancar pengeluaran ASI (Saryono \& RD Pramitasari, 2014).

Perawatan payudara adalah suatu tindakan untuk merawat payudara terutama pada masa nifas (masa menyusui) untuk memperlancarkan pengeluaran ASI. Manfaat perawatan payudara di antaranya dapat merangsang kelenjar air susu sehingga produksi ASI menjadi lancar dan mencegah penyumbatan pada payudara (Kumalasari, 2015).

Selama kehamilan, hormon prolaktin dari plasenta meningkat tetapi ASI biasanya belum keluar karena masih dihambat oleh kadar estrogen yang tinggi. Pada hari kedua atau ketiga pascapersalinan, kadar estrogen dan progesteron turun drastis, sehingga pengaruh prolaktin lebih dominan dan pada saat inilah mulai terjadi sekresi ASI. Kegiatan menyusukan lebih dini terjadi perangsangan puting susu, terbentuklah prolaktin oleh hipofisis, sehingga sekresi ASI semakin lancar. Dua refleks pada ibu yang sangat penting dalam proses laktasi, refleks prolaktin dan refleks aliran timbul akibat perangsangan puting susu oleh hisapan bayinya (Fatmawati, Syaiful, \& Wulansari, 2019). Setelah melahirkan, oksitosin juga mengencangkan otot halus di sekitar alveoli untuk memeras ASI menuju saluran susu. Pengeluaran ASI terjadi karena sel otot halus di sekitar kelenjar payudara mengerut sehingga memeras ASI untuk keluar, ASI dapat keluar dari payudara akibat adanya otot-otot yang mengerut yang dapat distimulasi oleh suatu hormon yang dinamakan oksitoksin (Rahayuningsih, Mudigdo, \& Murti, 2016).

Secara fisiologis perawatan payudara dengan merangsang buah dada akan 
mempengaruhi hypofise untuk mengeluarkan hormon progesteron dan estrogen lebih banyak lagi dan hormon oksitosin dengan merangsang kelenjarkelenjar air susu melalui pemijatan. Hal ini berkaitan dengan gerakan pada perawatan payudara bermanfaat melancarkan reflek pengeluaran ASI. Selain itu juga merupakan cara efektif meningkatkan volume ASI dan mencegah bendungan pada payudara (Fatmawati et al., 2019)

Penelitian ini sejalan dengan penelitian Meihartati (2016) yang menyatakan bahwa ada hubungan antara perawatan payudara dengan kejadian bendungan ASI. Penelitian Wulan dan Gurusinga (2019) mendapatkan ada pengaruh yang signifikan terhadap volume ASI pada ibu postpartum sebelum dan sesudah diberikan perawatan payudara (breast care).

Hasil penelitian Taqiyah, Sunarti, dan Rais (2019) mendapatkan sebelum dilakukan masase payudara terdapat $81,3 \%$ ibu postpartum yang dikategorikan mengalami bendungan ASI dan setelah dilakukan masase laktasi terjadi penurunan bendungan ASI dari $81,3 \%$ menjadi $18,8 \%$. Kesimpulan ada pengaruh masase laktasi terhadap bendungan ASI. Penelitian Prawita dan Salima (2018) mendapatkan ada hubungan pengetahuan dan sikap dengan pelaksanaan perawatan payudara di Klinik Pratama Niar Medan.

Hasil penelitian Tyfani, Utami, dan Susmini (2017) yang menyatakan bahwa pelaksanaan perawatan payudara akan memperlancar serta dapat meningkatkan produksi ASI ibu nifas. Semakin ibu melakukan perawatan payudara dengan baik maka ASI pun akan lancar. Pelaksanaan perawatan payudara sebaiknya dimulai sedini mungkin yaitu setelah bayi dilahirkan dan dilakukan dua kali sehari. Perawatan payudara dilakukan meliputi pengurutan payudara, pengosongan payudara, pengompresan payudara dan perawatan puting susu.

Menurut hasil analisa peneliti, mayoritas ibu nifas merupakan primipara, dimana mereka belum banyak mengetahui tentang perawatan pasca melahirkan, yang salah satunya adalah perawatan payudara. Hasil wawancara yang didapatkan ibu nifas tidak segera melakukan perawatan payudara pasca melahirkan sehingga mereka kesulitan dalam menyusui bayinya. Kebanyakan ibu nifas melakukan perawatan payudara ketika sudah merasakan tanda dan gejala terjadinya bendungan ASI, seperti payudara bengkak dan teraba hangat, serta ibu merasa demam. Selain itu juga, ibu nifas masih kurang informasi tentang cara dan teknik melakukan 
perawatan payudara yang benar, sehingga mengakibatkan produksi ASI sedikit dan asupan ASI yang diberikan kepada bayi kurang. Akibatnya, bayi mereka sering menangis dan ibu merasa cemas karena menganggap bayi mereka belum kenyang sehingga beberapa ibu nifas memutuskan untuk memberikan susu formula sebagai tambahan ASI yang kurang.

Masalah ini juga yang menyebabkan ibu tidak memberikan ASI eksklusif kepada bayi mereka. Sedangkan ibu nifas yang melakukan perawatan payudara, hanya sedikit yang melakukannya sesuai dengan prosedur dikarenakan pengalaman mereka sebelumnya dan diajarkan oleh ibu atau ibu mertua mereka.

Ibu nifas yang melakukan perawatan payudara selama menyusui berdampak baik sehingga tidak terjadi bendungan ASI. Gerakan pada perawatan payudara akan melancarkan reflek pengeluaran ASI, dapat mencegah dan mendeteksi dini kemungkinan adanya bendungan ASI, serta meningkatkan volume ASI sehingga gizi bayi terpenuhi dan pertumbuhan menjadi optimal.

Masih banyaknya ibu nifas yang tidak melakukan perawatan payudara disebabkan karena berbagai faktor yang mempengaruhi seperti ketidakmauan ibu melakukannya karena kurangnya kesadaran akan pentingnya merawat payudara dan tidak adanya waktu karena kesibukan sehari-hari. Selain itu juga dipengaruhi oleh kecemasan ibu yang dapat menyebabkan stres sehingga pengaruh ke hormon kortisol meningkat dan berdampak ke penurunan hormon oksitosin sehingga pengeluaran ASI tidak lancar.

\section{KESIMPULAN DAN SARAN}

\section{Kesimpulan}

Kesimpulan penelitian ini adalah ada hubungan perawatan payudara dengan kelancaran ASI pada ibu nifas. Kelemahan dari penelitian ini adalah tidak melihat secara langsung ketika ibu nifas melakukan perawatan payudara sebelum memberikan ASI kepada bayinya, tetapi peneliti hanya meminta kepada ibu nifas untuk mendemonstrasikan secara singkat cara melakukan perawatan payudara yang pernah dilakukan ataupun yang diketahui.

\section{Saran}

Berdasarkan hasil penelitian, sebagian besar ibu nifas masih memiliki pengetahuan yang kurang tentang perawatan payudara sehingga kesadaran akan pentingnya perawatan payudara untuk kelancaran ASI masih minim dan disarankan kepada ibu nifas agar melakukan perawatan payudara. Sebaiknya dilakukan setelah bayi lahir dan dilakukan teratur minimal 2 kali 
sehari pascapersalinan sehingga dapat merangsang kelenjar-kelenjar payudara untuk menghasilkan ASI.

Dianjurkan kepada petugas kesehatan khususnya perawat agar mengadakan penyuluhan dan mendemonstrasikan cara dan teknik perawatan payudara yang benar sebagai persiapan pada ibu hamil dan menyusui agar dapat memiliki produksi ASI cukup banyak dan lancar, sehingga nutrisi untuk anak dapat terpenuhi.

\section{DAFTAR PUSTAKA}

Dinas Kesehatan Provinsi Sumatera Utara. (2017). Profil Kesehatan Sumatera Utara Tahun 2017.

Fatmawati, L., Syaiful, Y., \& Wulansari, N. A. (2019). Pengaruh perawatan payudara terhadap pengeluaran ASI Ibu Post Partum [Jour]. Journals of Ners Community, 10(2), 169-184.

Kemenkes, R. I. (2017). Profil Kesehatan Republik Indonesia Tahun 2017 [Jour]. Kementerian Kesehatan RI. Jakarta.

Kumalasari, I. (2015). Panduan praktik laboratorium dan klinik perawatan antenatal, intranatal, posnatal bayi baru lahir dan kontrasepsi [Jour].

Lusje, K., Mandan, J., \& Kusmiyati, K. (2014). Hubungan rawat gabung dengan kelancaran produksi asi pada ibu post partum normal di Irina D Bawah BLU RSUP Prof. DR. RD Kandou Manado [Jour]. JIDAN (Jurnal Ilmiah Bidan), 2(1), 41-45.

Meihartati, T. (2016). Hubungan antara perawatan payudara dengan kejadian bendungan ASI pada ibu nifas di Poskesdes Sumber baru Kecamatan Angsana Kabupaten Tanah Bumbu. [Jour]. Kebidanan, 1.

Mochtar, R. (2015). Sinopsis Obstetri: Obstetri Fisiologi Obstetri Patologi Jilid I (Edisi 3; EGC, Ed.). Jakarta.
Notoatmodjo, S. (2012). Metodologi penelitian kesehatan (Cetakan VI) [JOUR]. Jakarta: Penerbit PT. Rineka Cipta.

Prawita, A. A., \& Salima, M. (2018). Hubungan pengetahuan dan sikap ibu nifas tentang perawatan payudara dengan pelaksanaan perawatan payudara di Klinik Pratama Niar Medan. Jurnal Bidan Komunitas. https://doi.org/10.33085/jbk.v1i3.399 1

Rahayuningsih, T., Mudigdo, A., \& Murti, B. (2016). Effect of Breast Care and Oxytocin Massage on Breast Milk Production: A study in Sukoharjo Provincial Hospital [Jour]. Journal of Maternal and Child Health, 1(2), 101-109.

Rosita, E. (2017). Hubungan perawatan payudara pada ibu nifas dengan bendungan ASI (Studi Di Desa Jolotundo dan Desa Kupang Kecamatan Jetis Kabupaten Mojokerto) [Jour]. Jurnal Kebidanan, 7(1).

Safitri, I., Wijayanti, A. C., \& Werdani, K. E. (2016). Faktor-faktor yang mempengaruhi kelancaran produksi ASI pada Ibu Menyusui di Desa Bendan, Kecamatan Banyudono, Kabupaten Boyolali [Diss]. Universitas Muhammadiyah Surakarta.

Saputri, Tri Muliani, dkk. (2017). Faktor yang berhubungan dengan kelancaran ASI pada Ibu Post Partum di RSKD Ibu dan Anak Siti Fatimah Makasar [Jour]. Jurnal Ilmiah Kesehatan Diagnosis, 10(1), 60-65.

Saryono dan RD Pramitasari. (2014). Perawatan Payudara (Nuha Medika, Ed.). Yogyakarta.

SDKI. (2017). Survei Demografi dan Kesehatan Indonesia 2017.

Suririnah. (2012). Persalinan (Gramedia Pustaka, Ed.). Jakarta.

Taqiyah, Y., Sunarti, S., \& Rais, N. F. (2019). Pengaruh perawatan payudara terhadap bendungan asi pada ibu postpartum di RSIA Khadijah I Makassar. Journal of Islamic

Nursing. 
https://doi.org/10.24252/join.v4i1.77 57

Tyfani, M. B., Utami, N. W., \& Susmini, S. (2017). Hubungan perawatan payudara terhadap kelancaran ASI Pada Ibu PostPartum di Kelurahan Tlogomas Kecamatan Lowokwaru Kota Malang [Jour]. Nursing News: Jurnal Ilmiah Keperawatan, 2(1).

WHO. (2015). World health statistics 2015. World Health Organization.

Wulan, S., \& Gurusinga, R. (2019). Pengaruh perawatan payudara (breast care) terhadap volume ASI pada ibu post partum (nifas) di RSUD Deli Serdang Sumut tahun 2012. Jurnal Kebidanan Harapan $\mathrm{Ibu}$ Pekalongan.

https://doi.org/10.37402/jurbidhip.vo 15.iss 1.16 